Article

\title{
Ultra-High Through-Cure of (Meth)Acrylate Copolymers via Photofrontal Polymerization
}

\author{
Catharina Ebner ${ }^{1}$, Julia Mitterer ${ }^{1}$, Paul Eigruber ${ }^{1}$, Sebastian Stieger ${ }^{2}$, Gisbert Riess ${ }^{1, *}$ and \\ Wolfgang Kern ${ }^{1}$ \\ 1 Department of Polymer Engineering and Science, Chair in Chemistry of Polymeric Materials, \\ Montanuniversitaet Leoben, 8700 Leoben, Austria; catharina.ebner@unileoben.ac.at (C.E.); \\ julia.mitterer@unileoben.ac.at (J.M.); paul.eigruber@unileoben.ac.at (P.E.); \\ wolfgang.kern@unileoben.ac.at (W.K.) \\ 2 Department of Polymer Engineering and Science, Chair of Injection Moulding of Polymers, \\ Montanuniversitaet Leoben, 8700 Leoben, Austria; sebastian.stieger@unileoben.ac.at \\ * Correspondence: gisbert.riess@unileoben.ac.at; Tel.: +43-3842-402-2301
}

Received: 14 May 2020; Accepted: 1 June 2020; Published: 4 June 2020

\begin{abstract}
Photopolymerization offers substantial advantages in terms of time, temperature, energy consumption, and spatial control of the initiation. The application however is strongly limited due to the constrained penetration of light into thick films. Strategies to overcome the problem of limited curing depth, as well as to improve the curing of shadow areas, involve dual curing, frontal polymerization, and upconversion of particles. Whereas excellent results have been accomplished applying photofrontal polymerization on a theoretical level, few studies report on practical applications achieving high curing depth within short time. This study aims to investigate the potential of photofrontal polymerization, performed only with photoinitiator and light, for the fast and easy production of several-centimeter-thick (meth)acrylic layers. Monomer/ initiator systems were evaluated with respect to their optical density as well as photobleaching behavior. Moreover, depth-dependent polymerization was studied in specimens of varying monomer ratio and photoinitiator concentration. When an ideal photoinitiator concentration was selected, curing up to $52 \mathrm{~mm}$ in depth was accomplished within minutes.
\end{abstract}

Keywords: photofrontal polymerization; photopolymerization; ultra-high through-cure; photobleaching; (meth)acrylate; macromonomers; TPO-L; type I photoinitiator

\section{Introduction}

Ultraviolet and, more recently, visible light have been used in industry for about 60 years to cure polymeric materials such as films, printing inks, coatings, dental composite resins, photoresists, as well as 3D printed parts in additive manufacturing [1-6]. In a light-induced radical polymerization, an initiator molecule is excited to higher energy levels by absorption of light, resulting in alpha or beta cleavage of a labile bond or abstraction of hydrogen, thus generating free radicals promoting polymerization in regions accessible to light. The fact that only areas exposed to light are cured allows controlled spatial polymerization and production of complex micro-scale structures with smooth surface $[7,8]$. Nevertheless, low penetration depths, caused by decreasing intensity according to Beer-Lambert law, greatly limit the application potential. Depending on the absorptivity of the formulation, the photoinitiator (PI) type, and the actinic source, layers with typically up to $50 \mu \mathrm{m}$ or at the very most a few millimeters thickness are commonly polymerized [9]. Various strategies have been developed to circumvent this limitation. Thermal frontal polymerization, for example, applies complementary initiators activated by heat generated in exothermic reactions. Thus, light induced 
polymerization reaches shadow areas and is able to cure large batches [10-14]. Upconverting (nano) particles, on the other hand, act as "internal lamps" by emitting photons within the bulk material. Liu et al. [15-17] employed this mechanism to cure a $8.4 \mathrm{~cm}$ thick thiol-ene system. Another promising and convenient method to cure systems consisting only of monomer(s) and photoinitiator involves photobleaching. Also known as photofrontal polymerization, this effect is based on the property of photoinitiators whose decay products exhibit an absorption behavior differing greatly from that of the initiator itself $[18,19]$. As a consequence, light penetrates deeper into a formulation in the course of irradiation and higher depth of cure (DOC) values are achieved (Figure 1a). Photoinitiators with photobleaching capability include substituted titanocenes, benzophenone, acylphosphine oxides (e.g., the trimethylbenzoyl phosphine oxide (TPO) family), and also 1,2-diones such as camphorquinone and its derivatives, which have gained interest due to their low volatility and good absorption in the visible spectrum [5,20-23]. According to previous studies, high curing depths of 10-13 cm may be achieved with photobleaching systems (PBS) $[9,24]$. Despite these promising approaches, only few studies did attempt to optimize photobleaching systems.

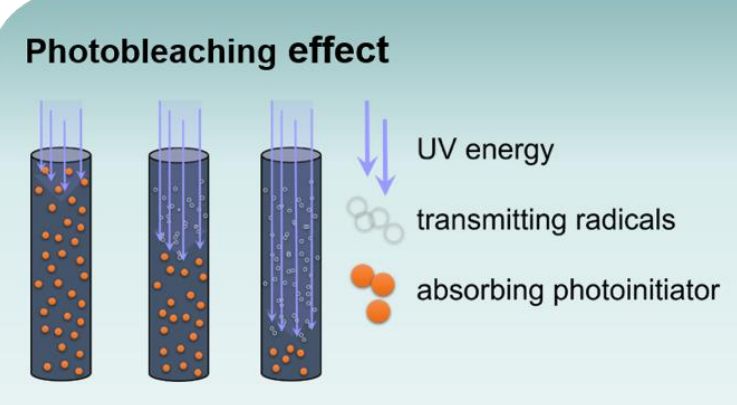

(a)

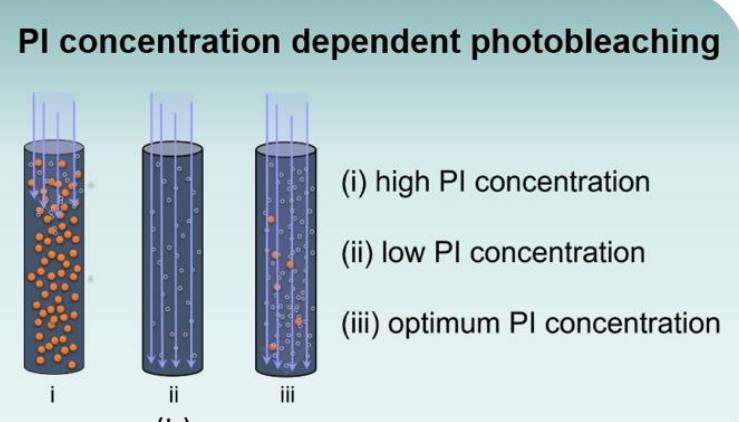

(b)

Figure 1. (a) Schematic representation of photofrontal polymerization, i.e., photobleaching during light exposure: absorbing photoinitiator (PI) molecules decompose into transparent products leading to an increase penetration depth. (b) PI concentration dependent penetration depth and curing: (i) high PI concentration resulting in increased absorption prevents deep penetration, (ii) low PI concentration enables high penetration depth with less radicals generated in the bottom region thus leading to low through-cure, (iii) with PI concentration in the optimum range, photobleaching allows light to penetrate into the bottom region still with enough radicals generated to achieve homogenous curing.

An efficient implementation, however, would offer significant benefits: Systems that achieve high DOC values due to photobleaching do not necessarily require additional initiators, expensive additives, or rare earths. Moreover, casting molds may ensure an efficient manufacturing of components in large quantities. In addition, high intensity curing systems are already available, which operate more sustainably, e.g., microwave power. State-of-the-art simulations provide an excellent basis for optimization [25-30]. Miller et al. presented a mathematical description of photopolymerization systems with photobleaching initiators [26]. According to their simulation, the spatial propagation of the initiation front is increased by enhancing the quantum yield and reducing the molar absorptivity of the monomers or the photolysis products. In investigating the dependency of curing depth on PI concentration, Lee et al. pointed to the presence of an optimum PI concentration for a given irradiation dose [31]. Two opposing effects play a role in this context: with a higher PI concentration the rate of radical formation will increase, but, in parallel, absorption of the formulation is raised, thus hindering penetration. Therefore, an optimum PI concentration should be low enough to allow deep penetration upon photobleaching but still high enough to generate a sufficient amount of initiating radicals for uniform curing (Figure 1b). Additional factors to be considered when designing photobleaching systems include the processing and optical characteristics of the matrix (i.e., molar absorptivity) as 
well as the emission output and intensity of the light source, which need to be reconciled with PI absorbance and concentration (Figure 2).

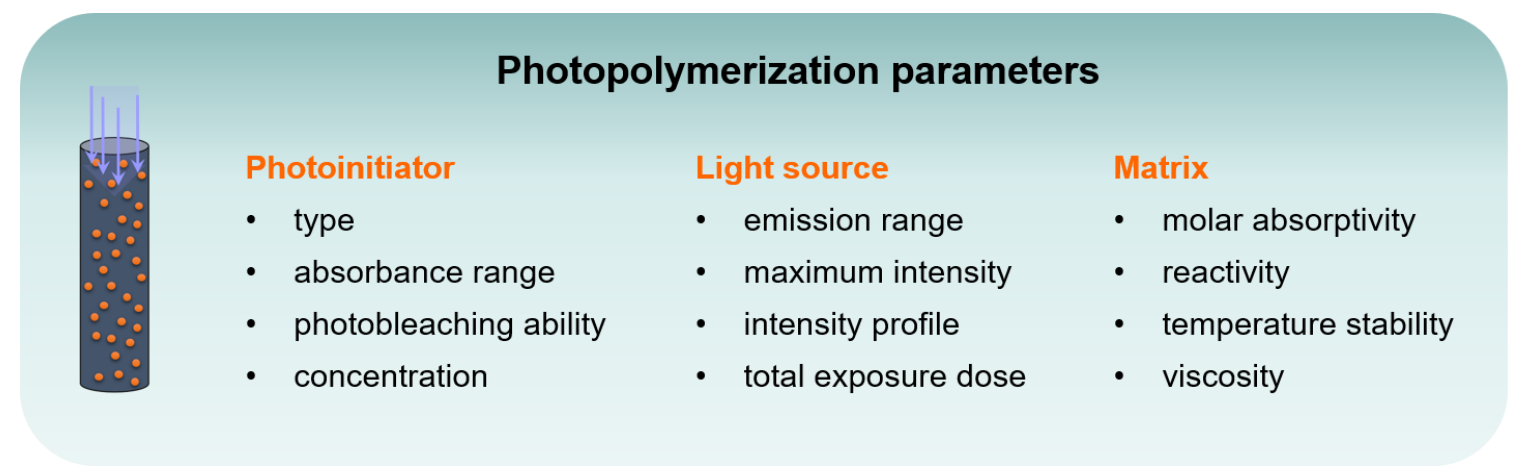

Figure 2. Key parameters for optimum curing (depth and photobleaching) in a light-induced radical polymerization.

Further, optimization of the intensity profile may be decisive for successful curing: Hayki et al. demonstrate that for full photobleaching a sigmoidal intensity profile leads to homogeneous radical formation from top to bottom, whereas for partial photobleaching an exponential intensity profile is beneficial [32]. Considering the mentioned parameters, the present study aims to explore the potential of photobleaching systems for the fast and easy production of thick (meth)acrylic layers in bulk. With a low optical density strategy in combination with TPO-L as highly efficient photobleaching initiator, a rapid homogenous through-cure of up to $52 \mathrm{~mm}$ thick specimens is accomplished. Offering resource-saving production and easy processing, polytetrahydrofuran methacrylates are particularly well suited for this purpose. Moreover, they are thermally stable and therefore tolerant to high intensity irradiation. Photopolymerizable systems consisting of long chain polytetrahydrofuran dimethacrylate as the crosslinker, 2-ethylhexyl acrylate as the reactive diluent, and TPO-L as the photoinitiator are characterized in this study.

\section{Materials and Methods}

\subsection{Materials}

Polytetrahydrofuran with an average molecular mass of $2900 \mathrm{~g} / \mathrm{mol}\left(\mathrm{PTHF}_{2900}\right)$, 2-ethylhexyl acrylate (2-EHA), methacrylic anhydride (MAA), as well as 2,6-di-tert-butyl-cresol (BHT) were purchased from Sigma Aldrich (Vienna, Austria) and used without further purification. 2,4,6-Trimethylbenzoylphenyl phosphinate (Omnirad TPO-L) was provided by IGM Resins (Walwijk, The Netherlands).

\subsection{Polyol Modification}

$\mathrm{PTHF}_{2900}$ modification was performed in bulk via microwave-assisted transesterification (3 min at $550 \mathrm{~W}$ for $150 \mathrm{~g}$ polyol) [33] with two fold molar excess of methacrylic anhydride. Subsequent vacuum distillation separate $\alpha, \omega$-polytetrahydrofuran-dimethacrylate $\left(\mathrm{PTHF}_{2900}-\mathrm{DM}\right)$ from unreacted methacrylic anhydride and methacrylic acid formed during the reaction. A total of 500 ppm of BHT, was added to the mixture to prevent unwanted polymerization. Modification and purity were monitored by ${ }^{1} \mathrm{H}-\mathrm{NMR}$ using a Varian 400 (Varian, Waldbronn, Germany) and ATR FT-IR (Vertex 70, Bruker, Ettlingen, Germany) spectroscopy. The developed procedure is completely solvent free and enables fast and easy recycling of excess methacrylic anhydride and methacrylic acid (Figure 3). 


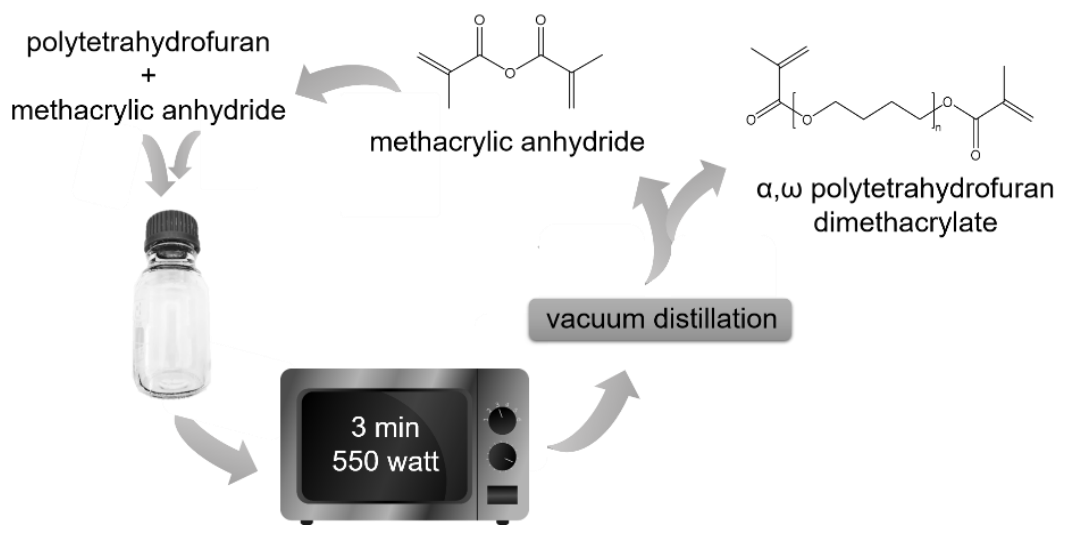

Figure 3. Microwave-induced transesterification of $\mathrm{PTHF}_{2900}$ with methacrylic anhydride followed by vacuum distillation, separating the highly temperature stable $\mathrm{PTHF}_{2900}$-DM from recyclable methacrylic anhydride and methacrylic acid.

\subsection{Preparation of Photobleaching Systems (PBS)}

Formulations containing $\mathrm{PTHF}_{2900}-\mathrm{DM}$, 2-EHA, and TPO-L were subjected to ultrasonication (water bath, $15 \mathrm{~min}, 50^{\circ} \mathrm{C}$ ) and mixed to homogeneity using VM-200 (StateMix, Winnipeg, Canada) prior to curing and characterization (Figure 4).

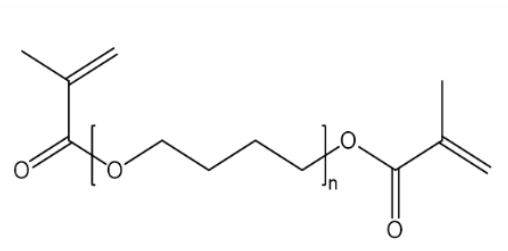

$\alpha, \omega$ polytetrahydrofuran dimethacrylate (PTHF-DM)<smiles>C=CC(=O)OCC(CC)CCC</smiles>

2- ethylhexyl acrylate (2-EHA)<smiles>CCOC(=O)C(=O)c1c(C)cc(C)cc1C</smiles>

2,4,6-trimethylbenzoylphenyl phosphinate (TPO-L)

Figure 4. Components of photobleaching systems: difunctional $\mathrm{PTHF}_{2900}-\mathrm{DM}$ and 2-ethylhexyl acrylate in combination with TPO-L.

\subsection{UV-Vis Spectroscopy and Photobleaching Experiments}

UV-Vis spectra of monomers and PBS were recorded using a Cary 50 UV-Vis spectrophotometer (Varian, Waldbronn, Germany). Determination of extinction $(E)$ followed Beer-Lambert law:

$$
E=\log _{10}\left(\frac{T_{0}}{T}\right)
$$

where $T_{0}$ denotes the incident transmittance and $T$ is the measured transmittance. The molar absorptivity $(\varepsilon)$ is determined according to:

$$
\varepsilon\left(L m o l^{-1} \mathrm{~cm}^{-1}\right)=\frac{E}{c \times d}
$$

where $c$ is the molar concentration and $d$ is the path length. To monitor photobleaching, $\mathrm{PTHF}_{2900}$-DM containing $0.15 \mathrm{wt} \%$ TPO-L was repeatedly subjected to a defined exposure dose using a Light Hammer 6 curing system (Fusion UV Systems, Gaithersburg, Maryland, US) equipped with semi-elliptical reflector, LC6B benchtop conveyor and a medium pressure mercury lamp (emission range between 250 and $470 \mathrm{~nm}$ ). The applied intensities and exposure dose in the sample plane were determined using UV Power Puck ${ }^{\circledR}$ II radiometer (EIT Instrument Markets, Sterling, Virginia, US) (Table 1). The total duration of the exposure was no more than a few minutes. A standard precision cuvette of $44 \mathrm{~mm}$ height 
(Hellma, 100-QA, one centimeter path length) with a removable light-shielding cover (several layers of aluminum foil) served as the mold. After each exposure cycle, transmittance was recorded in the spectral range between 200 and $800 \mathrm{~nm}$. Self-made cuvette inserts enabled height-resolved collection of spectra (i.e., at 2, 22, 32, and $42 \mathrm{~mm}$ ) to follow the progressing depth-dependent photobleaching from top to bottom. The light-shielding effect of the cover was tested beforehand by covering the top side with foil as well and applying the specified exposure. An unpolymerized (liquid) PBS proved that lateral exposure is negligible. Calculations of depth-dependent relative PI decay were based on changes in transmittance $(T)$ at $375 \mathrm{~nm}$ according to:

$$
\text { Relative PI }- \text { decay }=\frac{\Delta T}{\Delta T_{\max }} \times 100=\frac{T-T_{0}}{T_{\max }-\mathrm{T}} \times 100
$$

with $T_{0}$ as the absorbance before exposure and $T_{\max }$ the maximum absorbance obtained after full exposure.

Table 1. Exposure profile applied in photobleaching experiments.

\begin{tabular}{cccccc}
\hline Cycle & $\begin{array}{c}\text { Power Level } \\
(\mathbf{\%})\end{array}$ & $\begin{array}{c}\text { Intensity } \\
\left(\mathbf{w a t t ~} \mathbf{~ c m}^{-\mathbf{2}}\right)\end{array}$ & Runs & $\begin{array}{c}\text { Exposure Dose } \\
\left(\mathbf{J ~ c m}^{-2}\right)\end{array}$ & $\begin{array}{c}\text { Total Exposure Dose } \\
\left(\mathbf{J ~ c m}^{-2}\right)\end{array}$ \\
\hline 1 & 30 & 0.13 & 1 & 0.60 & 0.6 \\
2 & 30 & 0.13 & 1 & 0.60 & 1.2 \\
3 & 30 & 0.13 & 1 & 0.60 & 1.8 \\
4 & 30 & 0.13 & 1 & 0.60 & 2.4 \\
5 & 50 & 0.34 & 3 & 4.8 & 7.2 \\
6 & 60 & 0.48 & 3 & 6.8 & 14.0 \\
\hline
\end{tabular}

\subsection{Photopolymerization and Characterization of Curing Behavior}

Photobleaching systems for specimen production received a pretreatment as described in detail in Section 2.3. Polymerization was accomplished in cylindrically shaped Teflon ${ }^{\circledR}$ molds of $52 \mathrm{~mm}$ depth and one centimeter inner diameter with a total exposure of $20.8 \mathrm{~J} \mathrm{~cm}^{-2}$ after 9 runs (Table 2). Again, a cover of several layers aluminum foil prevented lateral exposure.

Table 2. Exposure profile applied for specimen production.

\begin{tabular}{|c|c|c|c|c|c|}
\hline Cycle & $\begin{array}{c}\text { Power Level } \\
(\%)\end{array}$ & $\begin{array}{c}\text { Intensity } \\
\text { (watt } \mathrm{cm}^{-2} \text { ) }\end{array}$ & Runs & $\begin{array}{c}\text { Exposure Dose } \\
\left(\mathrm{J} \mathrm{cm}^{-2}\right)\end{array}$ & $\begin{array}{l}\text { Total Exposure Dose } \\
\left(\mathrm{J} \mathrm{cm}^{-2}\right)\end{array}$ \\
\hline 1 & 40 & 0.24 & 3 & 3.4 & 3.4 \\
\hline 2 & 60 & 0.48 & 3 & 6.9 & 10.3 \\
\hline 3 & 100 & 0.96 & 3 & 10.5 & 20.8 \\
\hline
\end{tabular}

To assess the uniformity of polymerization, the specimens were sliced into five equal pieces and analyzed separately by swelling tests (including the determination of gel content) as well as FT-IR spectroscopy (Figure 5).

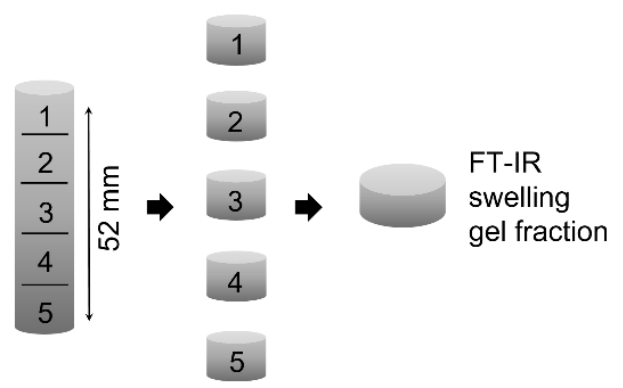

Figure 5. Sectioning of test specimen to evaluate depth-dependent curing. 
FT-IR spectroscopy was performed with an ATR (attenuated total reflection) accessory on a Vertex 70 (Bruker, Ettlingen, Germany) spectrometer in transmission mode with accumulation of 16 scans. In order to detect the mass loss of hydrophilic and hydrophobic components, ethanol and toluene served as solvents for swelling experiments. Specimen parts were allowed to swell for $240 \mathrm{~h}$ at $40^{\circ} \mathrm{C}$. The mass related solvent-uptake (swelling ratio $Q$ ) was determined according to:

$$
Q=\frac{w_{s}-w_{i}}{w_{i}}
$$

with $w_{\mathrm{i}}$ as initial mass of the polymeric network and $w_{\mathrm{s}}$ the mass of the swollen network. From the mass remaining after vacuum drying at $110{ }^{\circ} \mathrm{C}$ the gel-content was determined according to:

$$
\text { Gel-content }(\%)=\frac{w_{d}}{w_{i}} \times 100
$$

with $w_{d}$ as mass of the remaining dry network.

\section{Results and Discussion}

\subsection{Optical Characteristics of Monomers and Photobleaching Systems}

The absorptivity of monomers represents a major factor for deep curing and affects the ability of formulations to photobleach. Any absorption by the monomer, especially in the long or medium wave UV (UVA, UVB) or Vis region, would hamper deep penetration as it competes with the absorbance of the photoinitiator. Pure monomer formulations of $\mathrm{PTHF}_{2900}-\mathrm{DM}$ and 2-EHA are highly transmissive for light up to a wavelength of around 330 and $305 \mathrm{~nm}$ at one centimeter layer thickness (Figure 6a). Considering the emission spectrum of a conventional medium-pressure mercury lamp, which was used in this study, the monomers allow the strong UVA and Vis emission lines at 366 (i-line), 404 ( $h$-line), and $436 \mathrm{~nm}$ ( $g$-line) to penetrate almost unhindered. Being also transparent to the relatively strong UVB output line at $313 \mathrm{~nm}, 2$-EHA enables additional depth curing. These monomers are opaque at wavelengths below $305 / 320 \mathrm{~nm}$, and in particular the strong UVC line at $254 \mathrm{~nm}$ is limited to initiate polymerization in surface regions. The reduction in transmittance with increasing film thickness for $\mathrm{PTHF}_{2900}-\mathrm{DM}$ and 2-EHA is displayed in Figure 6a. Small differences in the absorption gain influence with increasing depth and have a considerable impact on curing. Phenol-based additives such as BHT show a tendency to yellowing, resulting in increased absorbance of $\mathrm{PTHF}_{2900}-\mathrm{DM}$ in $290-400 \mathrm{~nm}$ compared with 2-EHA [34].

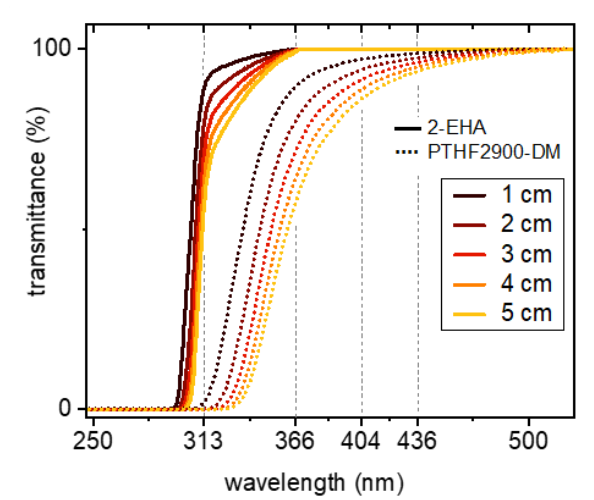

(a)

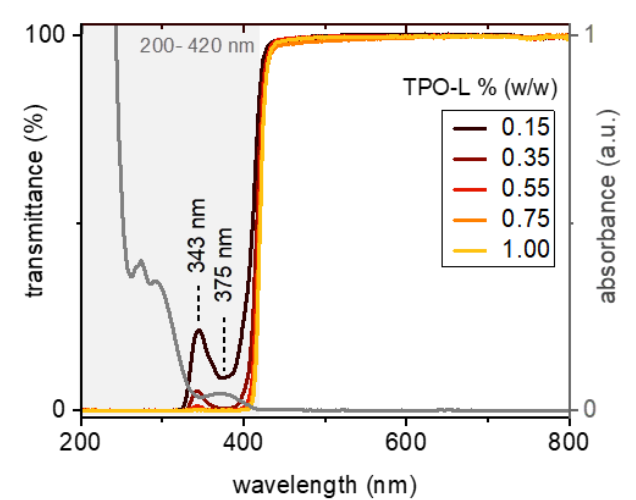

(b)

Figure 6. (a) Pure monomers, $\mathrm{PTHF}_{2900}-\mathrm{DM}$ and 2-EHA, transmit light down to wavelengths of 330 and $305 \mathrm{~nm}$, respectively, at one centimeter sample depth. The attenuation of light with increasing layer thickness is more pronounced with $\mathrm{PTHF}_{2900}-\mathrm{DM}$. (b) Upon TPO-L addition, transmittance decreases, starting from $420 \mathrm{~nm}$. Formulations with low TPO-L concentration (up to $0.55 \mathrm{wt} \%$ ) display maxima $(345 \mathrm{~nm})$ and minima $(375 \mathrm{~nm})$ in transmittance, reflecting the characteristic absorbance of TPO-L. 
PBS containing $\mathrm{PTHF}_{2900}-\mathrm{DM}$ and varying concentration of PI exhibit a strong reduction in transmittance below $420 \mathrm{~nm}$, with a transmission maximum at $345 \mathrm{~nm}$ and a minimum at $375 \mathrm{~nm}$, for PI concentration up to $0.55 \mathrm{wt} \%$ (Figure 6b). This reflects the characteristic absorbance pattern of the $\mathrm{PI}$, as is concluded from spectra of neat TPO-L $\left(10^{-5} \mathrm{M}\right.$ in ethanol). In case of PI concentration above $0.75 \mathrm{wt} \%$, light between 420 and $200 \mathrm{~nm}$ is fully absorbed at one centimeter path length. The low absorptivity of the monomers, along with the unambiguous assignment of peaks in the transmittance spectra of formulations containing TPO-L, provide a promising basis for photobleaching experiments and give a reason to expect high curing depths.

\subsection{Monitoring of Photobleaching}

With an assembly enabling height-resolved collection of spectra, the correlation between photoinitiator decay and increased penetration depth was investigated by UV-Vis spectroscopy. Photobleaching was monitored for a PBS of $\mathrm{PTHF}_{2900}-\mathrm{DM}$ containing $0.15 \mathrm{wt} \%$ TPO-L. Due to characteristic peaks, low PI concentration proves to be ideal when monitoring photobleaching, although possibly not sufficient for homogenous curing. The maximum depth $(44 \mathrm{~mm})$ results from the height of the employed standard cuvette. Prior to exposure, transmittance spectra identically reflect the absorbance characteristics of TPO-L with a minimum in transmittance at $375 \mathrm{~nm}$ (Figure 7a). After the first irradiation cycle $\left(0.6 \mathrm{~J} \mathrm{~cm}^{-2}\right)$, an overall increase in transmittance between 420 and 320 $\mathrm{nm}$ occurs up to a depth of $12 \mathrm{~mm}$. By enhancing the power level (intensity), the lower layers are reached as well (cycles 5 and 6, total exposure dose: 7.2 and $14.0 \mathrm{~J} \mathrm{~cm}^{-2}$ ). Finally, the spectra from top to bottom exhibit highly similar patterns converging to the spectrum of pure $\mathrm{PTHF}_{2900}-\mathrm{DM}$ (Figure 8a). Applying these settings (exposure system and PBS), it is possible to achieve photobleaching up to 42 $\mathrm{mm}$ depth, with a power level of $60 \%$ being sufficient to induce photoinitiator decay similar to that in near-surface regions. The clear specimen obtained from this experiment had reached gelation but was not tested in regard to homogenous curing because of the low photoinitiator concentration (Figure $7 \mathrm{~b}$ ).

(a)

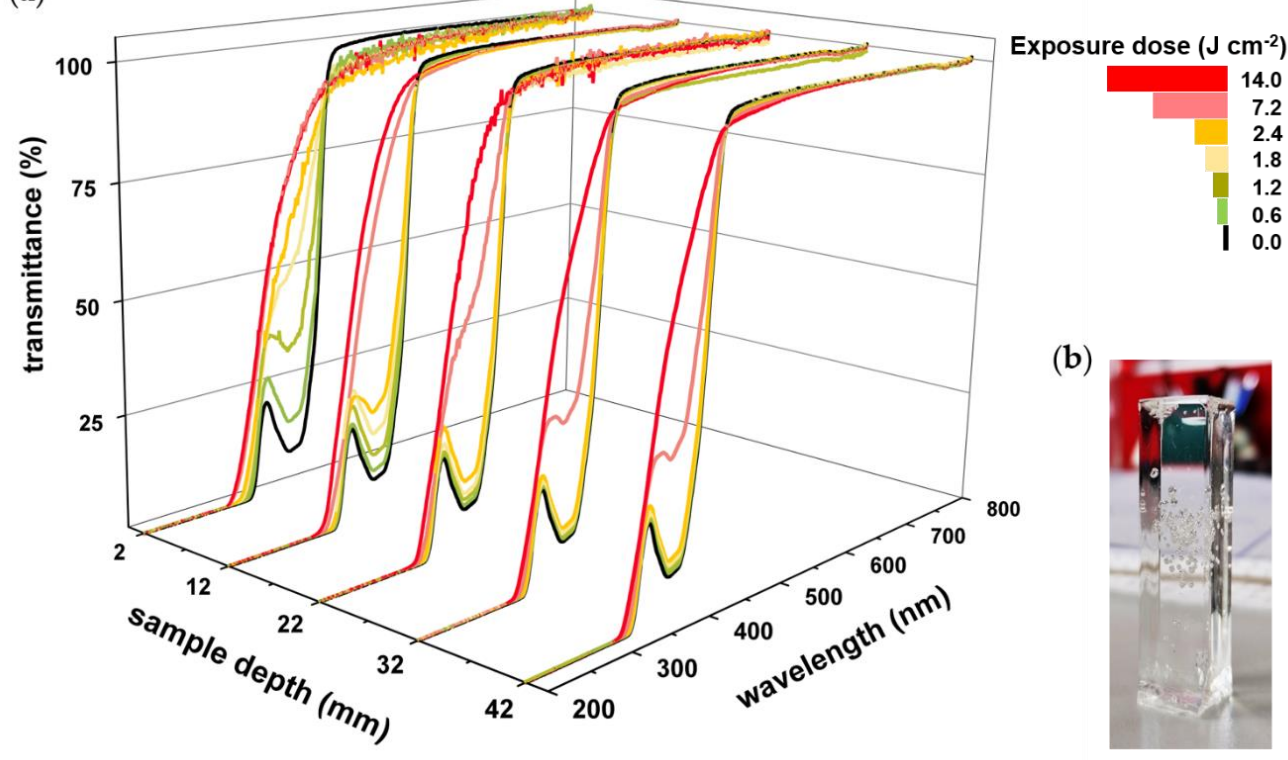

Figure 7. (a) Sample depth-dependent photobleaching of TPO-L in a bulk formulation containing $\mathrm{PTHF}_{2900}-\mathrm{DM}$ and $0.15 \mathrm{wt} \% \mathrm{PI}$. With increasing exposure dose and intensity, the transmittance between 420 and $320 \mathrm{~nm}$ increases from top $(2 \mathrm{~mm})$ to bottom $(42 \mathrm{~mm})$, reflecting progress in penetration depth and formation of free radicals through the entire sample depth. After the last irradiation cycle (total exposure $14.0 \mathrm{~J} \mathrm{~cm}^{-2}$ ) a uniform transmittance pattern of the $42 \mathrm{~mm}$ high specimen is achieved. (b) Cured specimen obtained after photopolymerization with an exposure dose of $14.0 \mathrm{~J} \mathrm{~cm}^{-2}$. 
Based on changes in transmittance at $375 \mathrm{~nm}$, the relative course of bleaching/photoinitiator decay is traced in detail (Figure 8b). At maximum exposure, decay rates at 12 and $22 \mathrm{~mm}$ appear to exceed those close to the surface, so that PI degradation seems less effective at $2 \mathrm{~mm}$ depth (92\%, normalized to the maximum decomposition observed at $12 \mathrm{~mm}$ ). As discussed earlier, this finding is attributed to a slight yellowing caused by the oxidation of phenol-based additives during exposure.

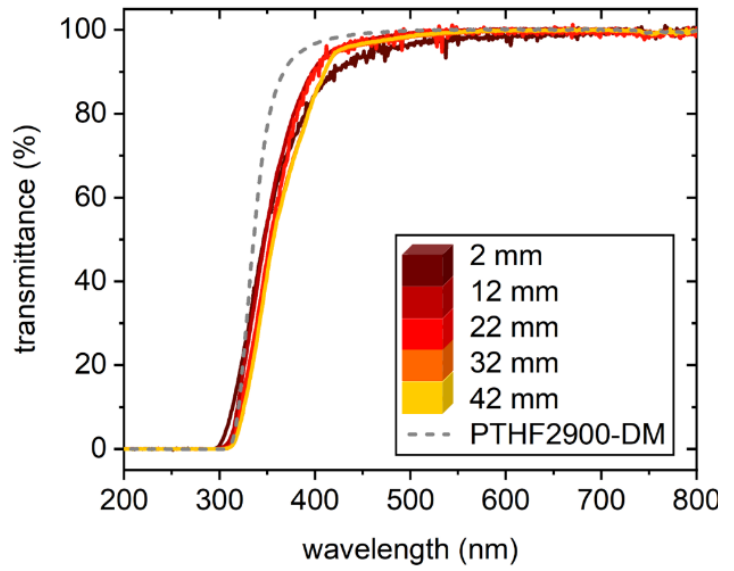

(a)

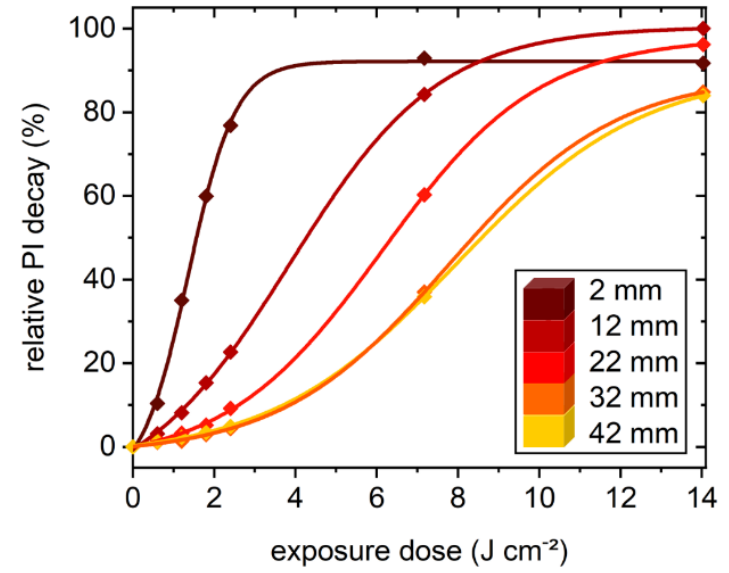

(b)

Figure 8. (a) Comparison of transmittance spectra at 2-42 $\mathrm{mm}$ after exposure with $14.0 \mathrm{~J} \mathrm{~cm}^{-2}$ indicates uniform bleaching; (b) normalized sample depth and exposure-dose-dependent photo initiator decomposition. With increasing dose, TPO-L decomposes gradually from top to bottom, ensuring progress in penetration depth and possibly high through-cure. At $42 \mathrm{~mm}$ depth, the maximum exposure dose leads to $84 \%$ decomposition (normalized to the maximum decomposition observed at a depth of $12 \mathrm{~mm}$ ).

\subsection{Polymerization Behavior of Photobleaching Systems}

Though photobleaching results are highly promising regarding PI decay and penetration depth, the experiments are not sufficient to provide information about the curing process itself. To gain an overview on polymerization behavior and cure depth, photobleaching systems A-F were investigated (Table 3). The used monomers differ greatly: $\mathrm{PTHF}_{2900}-\mathrm{DM}$ is of rather high viscosity (ca. $3500 \mathrm{~Pa}$ ) and implies a cross-linked polymer structure due to its difunctional nature, whereas 2-EHA serves as reactive diluent and generates linear polymers.

Table 3. Photobleaching systems for specimen production containing 0.5/1.0 wt \% TPO-L and varying ratio of $\mathrm{PTHF}_{2900}-\mathrm{DM}$ and 2-ethylhexyl acrylate.

\begin{tabular}{cccc}
\hline Photobleaching System & PTHF $_{\mathbf{2 9 0 0}}$ Dimethacrylate (wt $\left.\%\right)_{\text {) }}$ & 2-EHA (wt $\%)$ & TPO-L (wt $\%)$ \\
\hline A & 100 & 0 & 0.5 \\
B & 100 & 0 & 1.0 \\
C & 60 & 40 & 0.5 \\
D & 60 & 40 & 1.0 \\
E & 20 & 80 & 0.5 \\
F & 20 & 80 & 1.0 \\
\hline
\end{tabular}

Analysis of the curing behavior of these PBS under uniform conditions should provide insight on the influence of monomer ratio and photoinitiator amount. To allow sufficient photobleaching, the TPO-L concentration does not exceed $1.0 \mathrm{wt} \%$. The intensity profile is adapted to a total exposure dose of $20.8 \mathrm{~J} \mathrm{~cm}^{-2}$ (see also Section 2.5). After curing, $52 \mathrm{~mm}$ high, clear and uniform test specimens were released from the molds, sectioned and further characterized (Figure 9). Regardless of the PBS, a 
slight yellowing close to the surface was observed. It is assumed that the formation of quinones from BHT, triggered by UV irradiation and increased temperature, is responsible for the yellowing [33].

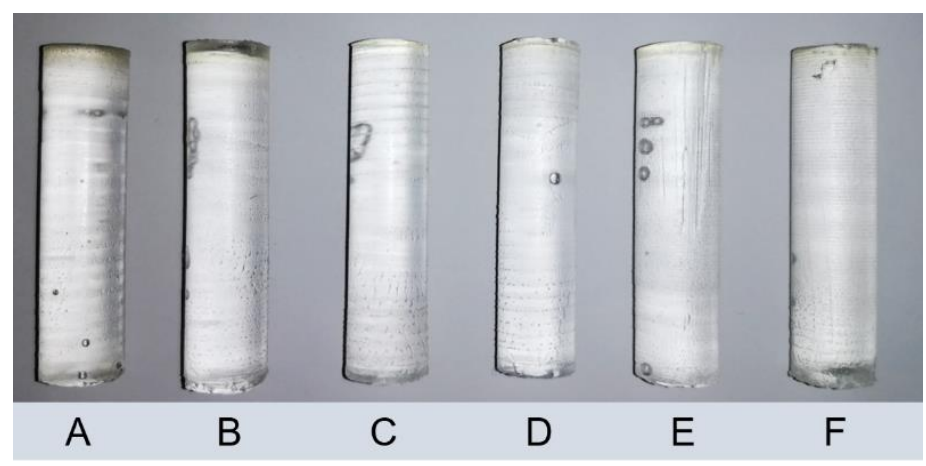

Figure 9. Depth cure of PBS A-F, and resulting specimens (height $52 \mathrm{~mm}$, diameter $10 \mathrm{~mm}$ ).

A first impression on through-cure was obtained through FT-IR spectroscopy of each section of the specimens (1-5, corresponding to the depth in $\mathrm{cm})$. PBS A exhibits consistent double bond conversion as indicated by disappearance of the corresponding peaks at $1635\left(\mathrm{C}=\mathrm{C}\right.$ stretch) and $653 \mathrm{~cm}^{-1}(\mathrm{C}-\mathrm{H}$ out of plane bending vibration) (Figure 10). However, due to the high molecular mass of $\mathrm{PTHF}_{2900}-\mathrm{DM}$, the peaks assignable to the double bond are poorly pronounced. A band appearing at $825 \mathrm{~cm}^{-1}$ after polymerization, which is primarily attributable to carbon-carbon skeletal vibration, superimposes the distinctive peak at $815 \mathrm{~cm}^{-1}$ (C-H out of plane bending vibration). Due to these difficulties and in view of the fact that all tested samples gave highly similar results, an exact quantification was omitted. Nevertheless, these results point to high double bond conversions.

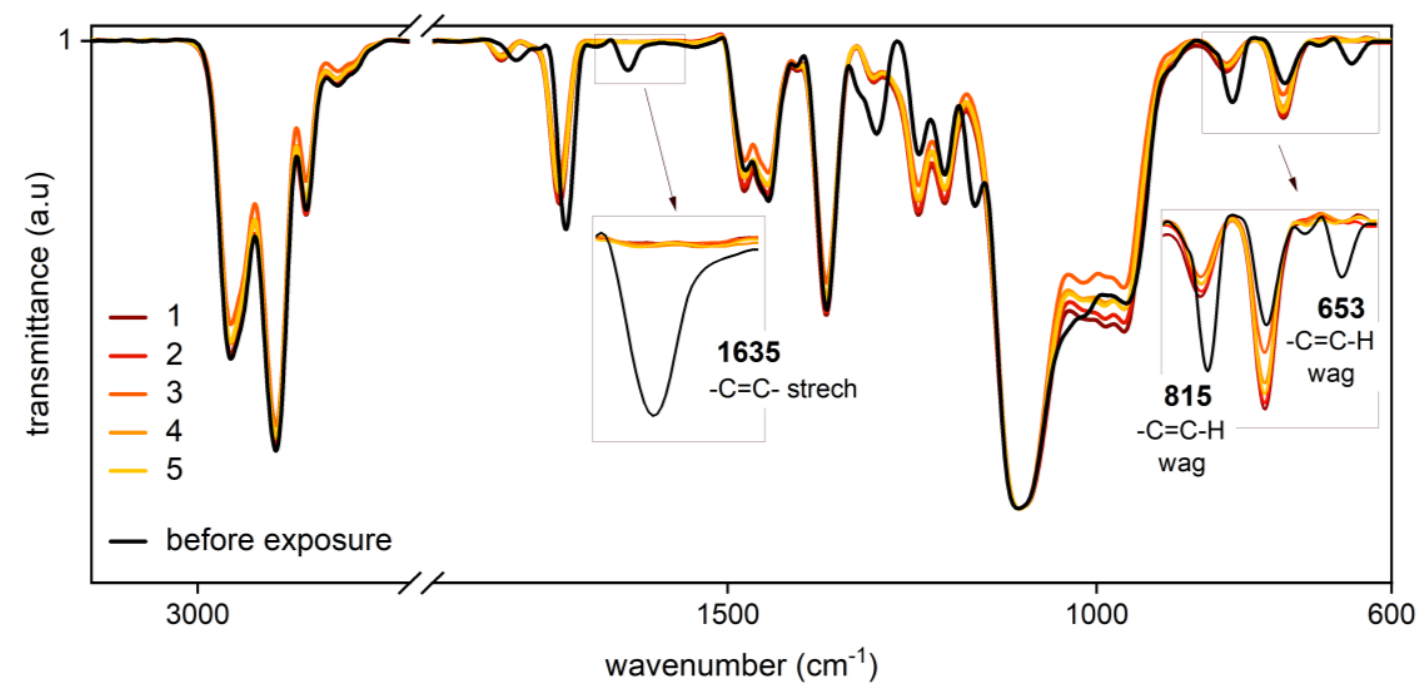

Figure 10. FT-IR spectroscopy of sections 1-5 (PBS A). The peaks related to carbon-carbon double bond units of the unpolymerized formulation at 1635,815 , and $653 \mathrm{~cm}^{-1}$ vanish in each section after light induced polymerization.

A deeper understanding of depth-dependent curing is obtained by determination of the gel content, taking into account the whole sample volume. Considering polar and non-polar components, separate swelling tests in ethanol and toluene were carried out (Figure S1a-d). The resulting gel contents draw a more differentiated picture than initially suggested from FT-IR measurements. Both monomer ratio and TPO-L concentration play a vital role in homogenous through-cure: By comparing gel contents of PBS A-C (0.5 wt \% TPO-L) in ethanol, a beneficial role of 2-EHA is suggested (Figure 11a). In PBS A the gel content decreases from $97 \%$ to $62 \%$, whereas PBS C polymerizes much more homogeneously (top 
(1) $94 \%$ to bottom (5) $86 \%$ ). These findings correlate with the UV-Vis data according to which 2-EHA features lower molar absorptivity than $\mathrm{PTHF}_{2900}-\mathrm{DM}$. In contrast, gel contents in toluene are below $90 \%$, though with higher consistency (Figure 11b). For photobleaching systems containing $1 \mathrm{wt} \%$ photoinitiator, the monomer ratio plays a subordinate role. Specimens D, E, and F exhibit gel contents above $90 \%$ along with excellent homogeneity (Figure 11c,d). Optimum conditions are met especially in PBS F, displaying uniform gel content from top to bottom, in both toluene and ethanol.

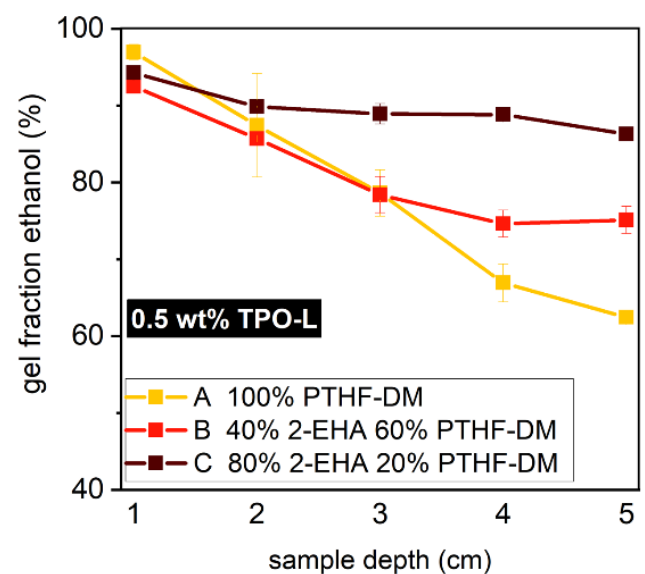

(a)

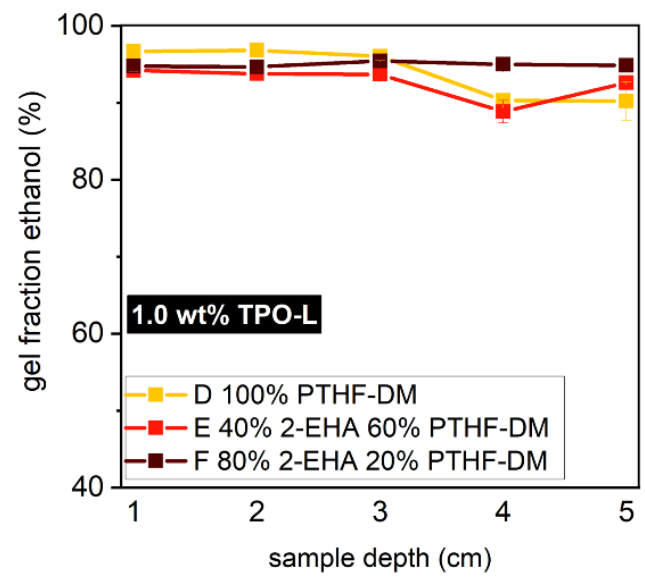

(c)

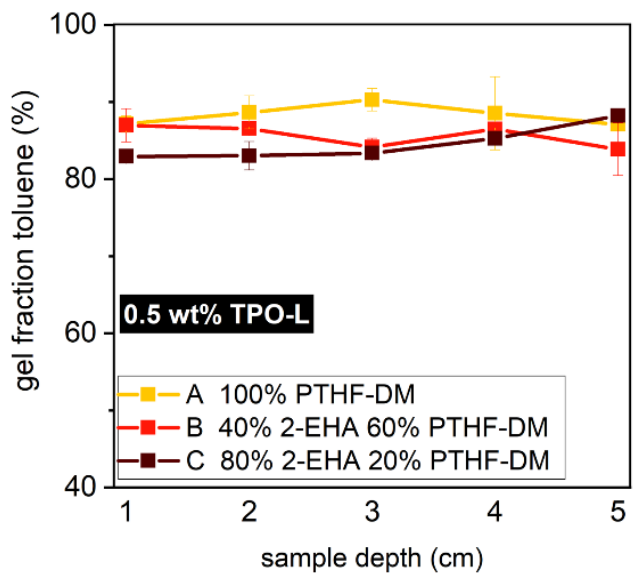

(b)

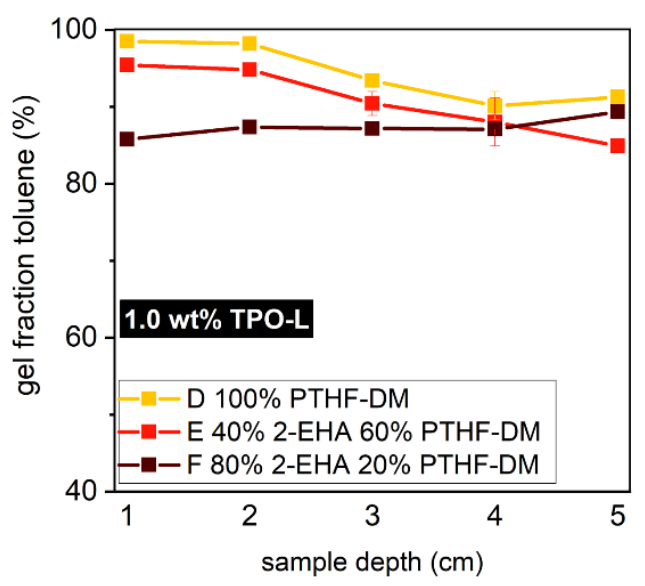

(d)

Figure 11. (a) Characteristics of the monomer composition play a key role in curing. For polymerization with $0.5 \mathrm{wt} \%$ TPO-L, a high quantity of 2-EHA appears beneficial. Gel contents below $90 \%$ are observed in toluene, though with high consistency (b). Regardless of the monomer composition and solvent, homogenous through-cure and uniform gel content are achieved using $1.0 \mathrm{wt} \%$ of photoinitiator (c,d).

\section{Conclusions}

This study examines the applicability of photofrontal polymerization for the fast and easy production of (meth)acrylic polymers in bulk. Six photobleaching systems of varying monomer ratio (PTHF 2900 -DM and 2-EHA) and TPO-L concentration were cured under uniform conditions and characterized with regard to homogenous polymerization. UV-Vis spectroscopy serves to determine depth-dependent transmittance of monomers, featuring low optical density especially in the UVA and Vis region. By employing self-made inserts for the spectrophotometer, bleaching from top to bottom was tracked precisely and indicated the decisive role of the applied intensity for in-depth radical formation. Declining gel contents were found for photobleaching systems containing $0.5 \mathrm{wt} \%$ initiator, 
and the effect is alleviated with increasing 2-EHA ratio, possibly due to its lower molar absorptivity (up to $305 \mathrm{~nm}$, compared to $320 \mathrm{~nm}$ for $\mathrm{PTHF}_{2900}-\mathrm{DM}$ ). For photobleaching systems containing $1 \mathrm{wt} \%$ TPO-L, excellent curing down to $52 \mathrm{~mm}$ in depth was found, regardless of the monomer ratio. This study demonstrates how to accomplish fast and easy photofrontal polymerization up to $52 \mathrm{~mm}$ in depth by appropriately selecting parameters such as monomer composition, concentration of the photoinitiator, as well as intensity and type of the light source. After optimizing all influencing factors, curing with an even higher depth and curing of thick films with inferior optical properties seem likely.

Supplementary Materials: The following are available online at http://www.mdpi.com/2073-4360/12/6/1291/s1, Figure S1a-d: Swelling ratios of specimens derived from PBS A-F in ethanol and toluene.

Author Contributions: Conceptualization, C.E., G.R.; methodology, C.E; formal analysis, C.E., J.M.; investigation, C.E., J.M., P.E.; data curation, C.E.; writing-original draft preparation, C.E.; writing-review and editing, G.R., S.S., W.K.; supervision, G.R., W.K.; All authors have read and agreed to the published version of the manuscript.

Funding: This research received no external funding.

Acknowledgments: In this section you can acknowledge any support given which is not covered by the author contribution or funding sections. This may include administrative and technical support, or donations in kind (e.g., materials used for experiments).

Conflicts of Interest: The authors declare no conflict of interest.

\section{References}

1. Steyrer, B.; Neubauer, P.; Liska, R.; Stampfl, J. Visible Light Photoinitiator for 3D-Printing of Tough Methacrylate Resins. Materials 2017, 10, 1445. [CrossRef] [PubMed]

2. Fouassier, J.P.; Allonas, X.; Burget, D. Photopolymerization reactions under visible lights: Principle, mechanisms and examples of applications. Prog. Org. Coat. 2003, 47, 16-36. [CrossRef]

3. Lorenz, H.; Despont, M.; Fahrni, N.; LaBianca, N.; Renaud, P.; Vettiger, P. SU-8: A low-cost negative resist for MEMS. J. Micromech. Microeng. 1997, 7, 121-124. [CrossRef]

4. Buonocore, M. Adhesive sealing of pits and fissures for caries prevention, with use of ultraviolet light. J. Am. Dent. Assoc. 1970, 80, 324-330. [CrossRef] [PubMed]

5. Green, W.A. Industrial photoinitiators. A Technical Guide; Taylor \& Francis: Boca Raton, FL, USA, 2010, ISBN 9781439827451.

6. Zhang, Z.; Corrigan, N.; Bagheri, A.; Jin, J.; Boyer, C. A Versatile 3D and 4D Printing System through Photocontrolled RAFT Polymerization. Angew. Chem. Int. Ed. Engl. 2019, 58, 17954-17963. [CrossRef]

7. Femmer, T.; Jans, A.; Eswein, R.; Anwar, N.; Moeller, M.; Wessling, M.; Kuehne, A.J.C. High-Throughput Generation of Emulsions and Microgels in Parallelized Microfluidic Drop-Makers Prepared by Rapid Prototyping. ACS Appl. Mater. Interfaces 2015, 7, 12635-12638. [CrossRef] [PubMed]

8. Männel, M.J.; Fischer, C.; Thiele, J. A Non-Cytotoxic Resin for Micro-Stereolithography for Cell Cultures of HUVECs. Micromachines 2020, 11, 246. [CrossRef]

9. Garra, P.; Dietlin, C.; Morlet-Savary, F.; Dumur, F.; Gigmes, D.; Fouassier, J.-P.; Lalevée, J. Photopolymerization processes of thick films and in shadow areas: A review for the access to composites. Polym. Chem. 2017, 8 , 7088-7101. [CrossRef]

10. Robertson, I.D.; Yourdkhani, M.; Centellas, P.J.; Aw, J.E.; Ivanoff, D.G.; Goli, E.; Lloyd, E.M.; Dean, L.M.; Sottos, N.R.; Geubelle, P.H.; et al. Rapid energy-efficient manufacturing of polymers and composites via frontal polymerization. Nature 2018, 557, 223-227. [CrossRef]

11. Pojman, J.A.; Ilyashenko, V.M.; Khan, A.M. Free-radical frontal polymerization: Self-propagating thermal reaction waves. Faraday Trans. 1996, 92, 2825. [CrossRef]

12. Bomze, D.; Knaack, P.; Koch, T.; Jin, H.; Liska, R. Radical induced cationic frontal polymerization as a versatile tool for epoxy curing and composite production. J. Polym. Sci. A Polym. Chem. 2016, 54, 3751-3759. [CrossRef]

13. Bomze, D.; Knaack, P.; Liska, R. Successful radical induced cationic frontal polymerization of epoxy-based monomers by C-C labile compounds. Polym. Chem. 2015, 6, 8161-8167. [CrossRef]

14. Knaack, P.; Klikovits, N.; Tran, A.D.; Bomze, D.; Liska, R. Radical induced cationic frontal polymerization in thin layers. J. Polym. Sci. A Polym. Chem. 2019, 57, 1155-1159. [CrossRef] 
15. Liu, R.; Chen, H.; Li, Z.; Shi, F.; Liu, X. Extremely deep photopolymerization using upconversion particles as internal lamps. Polym. Chem. 2016, 7, 2457-2463. [CrossRef]

16. Chen, Z.; Wang, X.; Li, S.; Liu, S.; Miao, H.; Wu, S. Near-Infrared Light Driven Photopolymerization Based On Photon Upconversion. ChemPhotoChem 2019, 3, 1077-1083. [CrossRef]

17. Oprych, D.; Schmitz, C.; Ley, C.; Allonas, X.; Ermilov, E.; Erdmann, R.; Strehmel, B. Photophysics of Up-Conversion Nanoparticles: Radical Photopolymerization of Multifunctional Methacrylates Comprising Blue- and UV-Sensitive Photoinitiators. ChemPhotoChem 2019, 3, 1119-1126. [CrossRef]

18. Pojman, J.A. Frontal Polymerization. Polymer Science: A Comprehensive Reference; Elsevier: Amsterdam, NL, USA, 2012; pp. 957-980. ISBN 9780080878621.

19. Carion, P.; Ibrahim, A.; Allonas, X.; Croutxé-Barghorn, C.; L'Hostis, G. Frontal free-radical photopolymerization of thick samples: Applications to LED-induced fiber-reinforced polymers. J. Polym. Sci. A Polym. Chem. 2019, 57, 898-906. [CrossRef]

20. Davidenko, N.; García, O.; Sastre, R. The efficiency of titanocene as photoinitiator in the polymerization of dental formulations. J. Biomater. Sci. Polym. Ed. 2003, 14, 733-746. [CrossRef]

21. Kolczak, U.; Rist, G.; Dietliker, K.; Wirz, J. Reaction Mechanism of Monoacyl- and Bisacylphosphine Oxide Photoinitiators Studied by 31 P-, 13 C-, and 1 H-CIDNP and ESR. J. Am. Chem. Soc. 1996, 118, 6477-6489. [CrossRef]

22. Kamoun, E.A.; Winkel, A.; Eisenburger, M.; Menzel, H. Carboxylated camphorquinone as visible-light photoinitiator for biomedical application: Synthesis, characterization, and application. Arab. J. Chem. 2016, 9, 745-754. [CrossRef]

23. Asmusen, S.; Arenas, G.; Cook, W.D.; Vallo, C. Photobleaching of camphorquinone during polymerization of dimethacrylate-based resins. Dent. Mater. 2009, 25, 1603-1611. [CrossRef] [PubMed]

24. Dolinski, N.D.; Page, Z.A.; Callaway, E.B.; Eisenreich, F.; Garcia, R.V.; Chavez, R.; Bothman, D.P.; Hecht, S.; Zok, F.W.; Hawker, C.J. Solution Mask Liquid Lithography (SMaLL) for One-Step, Multimaterial 3D Printing. Adv. Mater. Weinheim. 2018, 30, e1800364. [CrossRef] [PubMed]

25. Terrones, G.; Pearlstein, A.J. Effects of Optical Attenuation and Consumption of a Photobleaching Initiator on Local Initiation Rates in Photopolymerizations. Macromolecules 2001, 34, 3195-3204. [CrossRef]

26. Miller, G.A.; Gou, L.; Narayanan, V.; Scranton, A.B. Modeling of photobleaching for the photoinitiation of thick polymerization systems. J. Polym. Sci. A Polym. Chem. 2002, 40, 793-808. [CrossRef]

27. Lin, J.-T.; Liu, H.-W.; Chen, K.-T.; Cheng, D.-C. Modeling the Optimal Conditions for Improved Efficacy and Crosslink Depth of Photo-Initiated Polymerization. Polymers 2019, 11, 217. [CrossRef] [PubMed]

28. O'Brien, A.K.; Bowman, C.N. Modeling Thermal and Optical Effects on Photopolymerization Systems. Macromolecules 2003, 36, 7777-7782. [CrossRef]

29. Zhang, Y.; Kranbuehl, D.E.; Sautereau, H.; Seytre, G.; Dupuy, J. Modeling and Measuring UV Cure Kinetics of Thick Dimethacrylate Samples. Macromolecules 2009, 42, 203-210. [CrossRef]

30. Ivanov, V.V.; Decker, C. Kinetic study of photoinitiated frontal polymerization. Polym. Int. 2001, 50, 113-118. [CrossRef]

31. Lee, J.H.; Prud'homme, R.K.; Aksay, I.A. Cure depth in photopolymerization: Experiments and theory. J. Mater. Res. 2001, 16, 3536-3544. [CrossRef]

32. Hayki, N.; Lecamp, L.; Désilles, N.; Lebaudy, P. Kinetic Study of Photoinitiated Frontal Polymerization. Influence of UV Light Intensity Variations on the Conversion Profiles. Macromolecules 2010, 43, 177-184. [CrossRef]

33. Van Hove, A.H.; Wilson, B.D.; Benoit, D.S.W. Microwave-assisted functionalization of poly(ethylene glycol) and on-resin peptides for use in chain polymerizations and hydrogel formation. J. Vis. Exp. 2013, e50890. [CrossRef] [PubMed]

34. Bangee, O.D.; Wilson, V.H.; East, G.C.; Holme, I. Antioxidant-induced yellowing of textiles. Polym. Degrad. Stab. 1995, 50, 313-317. [CrossRef]

(C) 2020 by the authors. Licensee MDPI, Basel, Switzerland. This article is an open access article distributed under the terms and conditions of the Creative Commons Attribution (CC BY) license (http://creativecommons.org/licenses/by/4.0/). 